\title{
High Temperature Discontinuous Yielding in a New Near $\beta$ Titanium Alloy Ti-7333
}

\author{
Fan Jiangkun, Kou Hongchao, Lai Minjie, Tang Bin, Chang Hui, Li Jinshan
}

State Key Laboratory of Solidification Processing, Northwestern Polytechnical University, Xi'an 710072, China

\begin{abstract}
The high temperature discontinuous yielding behavior of Ti-7333 (Ti-7Mo-3Nb-3Cr-3Al), a new near $\beta$ titanium alloy, has been examined between 770 and $845^{\circ} \mathrm{C}$ over strain rates from $10^{-3} \mathrm{~s}^{-1}$ to $1 \mathrm{~s}^{-1}$. The results show that the discontinuous yielding of the alloy occurs when its strain rate is above $10^{-2} \mathrm{~s}^{-1}$ at all the experimental temperatures. The magnitude of the discontinuous yield drop for Ti-7333 alloy increases with decreasing of strain rate at a fixed temperature, and decreases with decreasing of temperature at a fixed strain rate. The magnitude is more sensitive to the strain rate than the temperature in this investigation. The discontinuous yield phenomena observed is associated with the mobile dislocation generated in grain boundaries during plastic deformation spreading to the grain interior with increasing of strain. The grain boundaries act as the sources of mobile dislocation generation. Further analysis suggests that the discontinuous yield drop is related to unlocking of dislocation sources through a localized dislocation climb, a boundary migration and/or a solute rearrangement.
\end{abstract}

Key words: Ti-7333; near $\beta$ titanium alloy; discontinuous yielding; high temperature; strain rate; dislocation

Discontinuous yielding is an interesting phenomenon, had its stress-train curves exhibits a sharp initial peak stress during the deformation. Such phenomenon was also reported to be present in many other beta titanium alloys, including Ti-5553 and Ti-1300 alloys ${ }^{[1,2]}$. Actually, these observations have been explained by static theory and dynamic theory ${ }^{[3]}$. The two theories have the same foundation, which is a low mobile dislocation density in the material before deformation. The initial mobile dislocation density of the specimens in this study is assumed to be low for two reasons ${ }^{[4]}$. Firstly, the dislocations would be annihilated during the heating process and holding time before the compression. Secondly, the dislocations would be pinned by the solute atoms and become immobile. The investigation of Ti-4Al-4Mo-2Sn- $0.5 \mathrm{Si}$ by Robertson et al. ${ }^{[5]}$ found that the discontinuous yielding is more obvious under a higher temperature and a higher strain rate. Except deformation conditions, both the alloy composition and the type of solid solution element affect the yielding significantly ${ }^{[6]}$. The extent of the abrupt flow stress reduction during low strain deformation has been found to be composition dependent, and increasing solute content tends to increase the magnitude of the yield drop. Further, the solute type also appears to be important, and increasing solute-titanium atomic size differential, leads to an increase in the magnitude of the yield drop. In addition, Long and Rack found that the magnitude of discontinuous yielding was a function of grain size ${ }^{[7]}$. As the grain size increases, the magnitude of the discontinuous yielding drop decreases.

From the above, significant effort has been made to investigate the discontinuous yielding phenomenon of various alloys, especially the iron-carbon alloy ${ }^{[8]}$ and superalloy ${ }^{[9]}$. Unfortunately, little comprehensive work and analysis have been conducted concerning the phenomenon for $\beta$ titanium alloy. Nowadays, a new near beta titanium alloy Ti-7333 with a ultrahigh tensile strength and a reasonable ductility after subtransus solution followed by aging treatment has been developed in China ${ }^{[10]}$. The balancing strength and ductility make it promising application in the field of aerospace.

Received date: April 10, 2013

Foundation item: The Project of Introducing Talents of Discipline to Universities (B08040); The International Cooperation Fund of the State Key Laboratory of Solidification Processing in NWPU

Corresponding author: Fan Jiangkun, Ph. D., State Key Laboratory of Solidification Processing, Northwestern Polytechnical University, Xi'an 710072, P. R. China, Tel: 0086-29-88460568, E-mail: fjk2006ok@163.com

Copyright $($ C 2014, Northwest Institute for Nonferrous Metal Research. Published by Elsevier BV. All rights reserved. 
However, hot deformation following solid solution is a necessary process before completing manufacture. Thus, in the present work, with the help of hot compression tests, the flow behavior and the discontinuous yielding occurring in the process were investigated in order to understand the mechanism more clearly and provide a theoretical basis for hot deformation of the new near $\beta$ alloy.

\section{Experiment}

The investigated alloy, Ti-7333 (7.18Mo-2.99Nb-2.94Cr$3.00 \mathrm{Al}-0.038 \mathrm{Fe}-0.11 \mathrm{O}$, wt $\%$ ), was obtained from a partially $(\alpha+\beta)$ processed billet, the microstructure of which is shown in Fig.1a. Apparently, the forging state microstructure consists of elongated and fractured $\beta$ grains. Within the $\beta$ matrix, small globular $\alpha$ phase particles can be observed. The $\beta$ transus temperature of Ti-7333 alloy, measured metallographically, is approximately $850{ }^{\circ} \mathrm{C}$.

Isothermally hot compression tests were conducted on Gleeble-3800 thermal and mechanical simulator using cylindrical samples with $12 \mathrm{~mm}$ in height and $8 \mathrm{~mm}$ in diameter. All compression samples were solution-treated at $900{ }^{\circ} \mathrm{C}$ for $30 \mathrm{~min}$ followed by water quenching. The starting microstructure of Ti-7333 alloy used for testing is shown in Fig.1b, where only coarse $\beta$ grains can be seen. Two end faces of deformed specimens were perpendicular to the compression axis, and all sides were mechanically ground to minimize friction. A thermocouple welded at mid span of the specimens was used to measure and control the processing temperature. The compressive tests were performed within temperature range of $770 \sim 845{ }^{\circ} \mathrm{C}$ and at strain rates from $10^{-3} \mathrm{~s}^{-1}$ to $1 \mathrm{~s}^{-1}$. The specimens were heated to processing temperatures at the rate

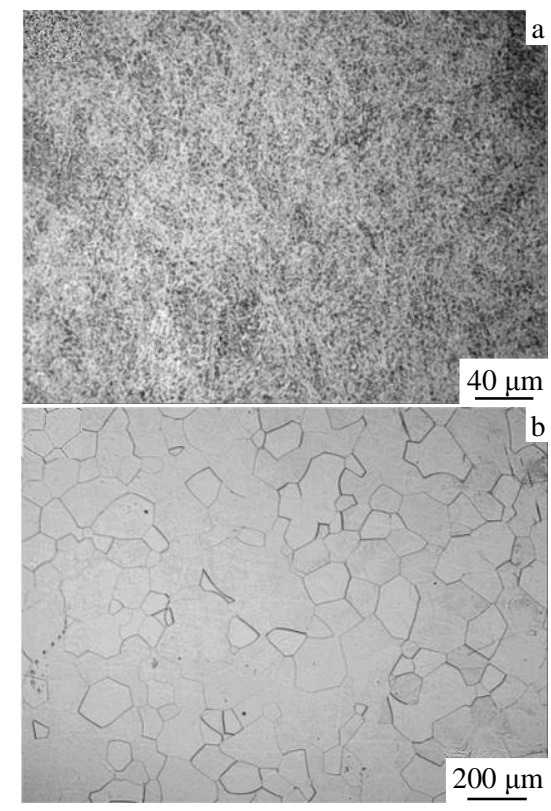

Fig.1 Initial microstructures of Ti-7333 alloy: (a) forging state and (b) solid solution treatment state of $25{ }^{\circ} \mathrm{C} / \mathrm{min}$ and then held for $2 \mathrm{~min}$ before the commencement of deformation to ensure homogeneous temperature fields. The maximum height reduction was $70 \%$. Upon the completion of compression procedure, each specimen was water-quenched immediately to retain the deformed microstructures for microstructural investigations. The specimens were etched by Kroll's reagent $(10 \mathrm{~mL} \mathrm{HF}+20$ $\mathrm{mL} \mathrm{HNO}_{3}+70 \mathrm{~mL} \mathrm{H}_{2} \mathrm{O}$ ) and the microstructure examination was conducted at an OLYMPUS/GX51 optical microscope.

\section{Results and Discussion}

Fig.2 depicts the true stress-strain curves of Ti-7333 alloy under different conditions. These curves show that the flow stress decreases with the increase of deformation temperature at a given strain rate, and increases with the increase of strain rate at a given temperature. In addition, the flow curves all exhibit a limited work hardening, and for higher strain rates a significant flow softening occurs after yielding drop followed by a steady state flow, which might result from a dynamic recover (DRV) and a dynamic re-crystallization (DRX) ${ }^{[11,12]}$.

As illustrated in Fig.2a, the stress-train curves at strain rate of 0.1 and $1 \mathrm{~s}^{-1}$ exhibit an obviously sharp initial peak stress, which is related to a discontinuous yielding phenomenon, followed by a little work hardening and then softening to a steady state. Decreasing strain rate results in the elimination of the strain hardening at all temperatures in the present investigation, discontinuous yielding and steady-state flow can be observed. Finally, at the lowest strain rates, $10^{-3}$ and
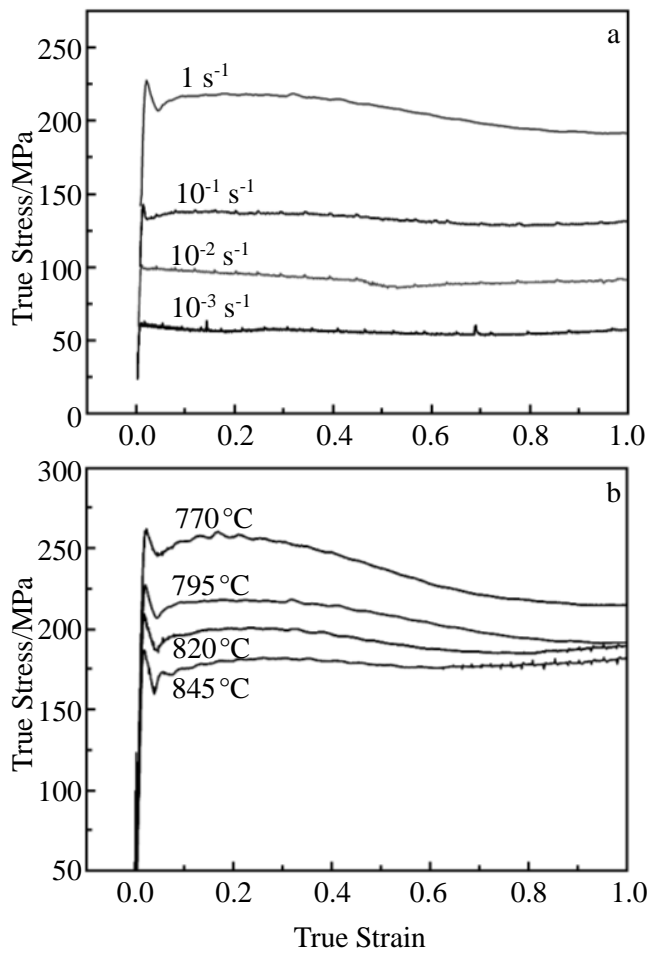

Fig.2 True stress-true strain curves of Ti-7333 alloy at $795{ }^{\circ} \mathrm{C}$ (a) and $1 \mathrm{~s}^{-1}(\mathrm{~b})$ 
$10^{-2} \mathrm{~s}^{-1}$, discontinuous yielding is hardly observed. Besides, the discontinuous yielding is more obvious at higher temperature, as shown in Fig.2b.

The magnitude of the discontinuous yielding is a function of both strain rate and temperature, as shown in Fig.3. For example, independent of strain rate, the magnitude of the discontinuous yield drop exhibits a maximum with increasing of test temperature. Further as the strain rate increases, at fixed deformation temperature, the magnitude of the discontinuous yield drop increases. These conclusions are similar to the study of Robertson et $\mathrm{a}^{[5]}$. The most obvious discontinuous yielding can be observed mainly at $1 \mathrm{~s}^{-1}$ and the magnitude reaches $29 \mathrm{MPa}$. The growth rate of the yielding drop magnitude increases with increasing of strain rate in the experimental temperature range. However, the magnitude of the discontinuous yielding is more sensitive to strain rate than temperature in the present investigation.

By comparison with other near $\beta$ titanium alloys ${ }^{[13,14]}$, the flow stress dependence on strain rate and temperature shows excellent agreement. The yield drop levels are of the same magnitude as that of Ti-7333 alloy deformed under the same conditions. In addition, the flow stress of Ti-7333 alloy is slightly lower than those of Ti-1023 ${ }^{[15,16]}$ and Ti-5553 ${ }^{[1]}$ alloys at the same strain rate. It should be related to the solid solution strengthening contribution of some alloying elements.

The discontinuous yielding could be described by the static theory, in which, the stress peak could be related to the presence of $\beta$ stabilizers. The dislocations originally contained within a material are assumed to be immobilized or locked by solute atoms, as shown in Fig.4a. Upon application of a sufficiently high applied stress, these dislocations are able to break away from their pinning points, thereby creating a higher density of mobile dislocations which can now propagate and multiply at reduced stress levels, as was studied by Jonas et al. ${ }^{[17]}$. However, the effect of deformation temperature and strain rate on the yielding behavior could not be explained properly by the static theory. Actually, it is hard to pin the dislocations efficiently by alloy elements and impurities at high temperature. And the discontinuous yielding

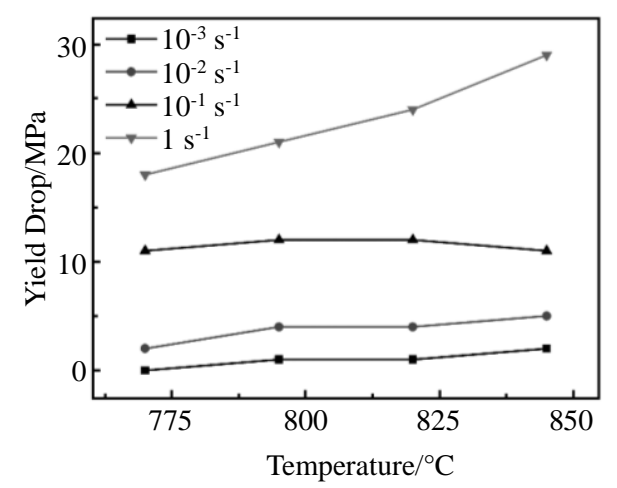

Fig.3 Magnitude of yield drop in Ti-7333 alloy as a function of temperature and strain rate of most titanium alloys has the positive temperature sensitivity. Thus, it is bound to cause some doubt on the static theory which is suitable for hot deformation of titanium alloy or not. Later, Ankem ${ }^{[18]}$ and Weiss ${ }^{[6]}$ further denied the explanation of static theory to discontinuous yielding by high temperature experiments.

Thus, if this phenomenon is related to the dynamic theory, summarized by Long and $\operatorname{Rack}^{[7]}$, the higher content of the $\beta$-stabilizers in $\beta$ phase, either in the near grain boundaries or within the grain, can intensify the solute-dislocation interaction, provoking a reduction of the mobile dislocation density. Consequently, new mobile dislocations must be generated upon deformation, with grain boundaries acting as sources.

According to the dynamic theory, the abundant dislocations generated at grain boundaries piled up due to the obstacle of grain boundaries (Fig.4b). Thus, the flow stress rises sharply. Dynamic recovery enhances abruptly when the dislocation density reaches a critical value, resulting in a significant drop of flow stress, so the discontinuous yielding emerges. The mobile dislocations multiplication abruptly is related to graining boundaries, so the smaller the grain size, the more abundant the grain boundaries, and then the more significant the discontinuous yielding. The relationship between dislocation density and grain size can be expressed as

$$
\rho=2 \sqrt{3}\left(\varepsilon^{2}\right)^{\frac{1}{2}} /(D * b)
$$

Where, $\rho$ is dislocation density, $\left(\varepsilon^{2}\right)^{\frac{1}{2}}$ is average microstrain, $D$ is grain size, and $b$ is burgers vector ${ }^{[19]}$. This fitted the experiment results by Long and $\operatorname{Rack}^{[7]}$. The precondition of discontinuous yielding is that the dislocation density reaches a critical value, and thus it needs a high enough strain rate to ensure the accumulation of dislocation density. That is why the discontinuous yielding easily occur at higher strain rate, as shown in Fig.2a. The mobile dislocations multiplication abruptly is essentially due to the sudden intensification of dynamic recovery, and thus the higher the temperature, the greater the driving force, and then the more significant the discontinuous yielding (Fig.2b). Obviously, the dynamic theory explains the discontinuous yielding behavior of Ti-7333 alloy during hot deformation. According to the equations of dislocation multiplication theory $\& b \rho v$, once strain rate \& increases, the velocity of mobile dislocations $v$ is required to increase, and then the applied stress $\sigma$ also increases, as shown in Fig.2.

The microstructure of the specimen deformed at $770{ }^{\circ} \mathrm{C}$ and $1 \mathrm{~s}^{-1}$ to a true strain of 0.02 are shown in Fig.5. The clear evidence for grain boundary associated dislocation generation shows that the intensity of this generation varies along the grain boundary, and it is the most intense at triple points. They also provide support for the dynamic theory of the discontinuous yielding, the origin of mobile dislocations being grain 

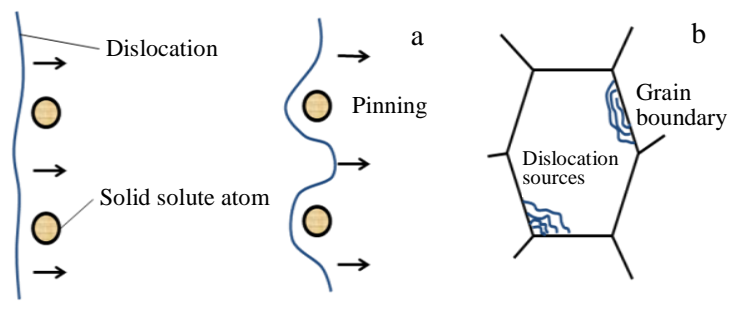

Fig.4 Schematic of pinning dislocation: (a) static theory and (b) dynamic theory

boundary dislocation sources.

It also can be seen from Fig.5 that little alpha phase nucleates and grows randomly inside beta grains due to deforming in the $\alpha+\beta$ region; besides, the small alpha precipitates prefer to nucleate and grow in the regions with a high density of dislocations. In titanium alloys, the elements $\mathrm{Al}$ and $\mathrm{Sn}$ could have the segregation at the region of a dislocation expanding area, while Mo, Zr, etc. or rare-earth elements segregate at the region of dislocation core region, and thus the alloy element concentration is higher than the perfect crystal. It provides an advantageous condition for the precipitation of $\alpha$ phase $^{[20]}$.

According to our previous work ${ }^{[21]}$, the activation energy $Q$ at different temperatures and stain rates can be calculated. The activation energy of deformation is calculated to be 329 $\mathrm{kJ} / \mathrm{mol}$, which is much higher than the self-diffusion activation energy of $\beta$ titanium alloy known as $153 \mathrm{~kJ} / \mathrm{mol}^{[22]}$. Conceptually, this suggests that the effects of temperature on the magnitude of the discontinuous yield drop may be related to

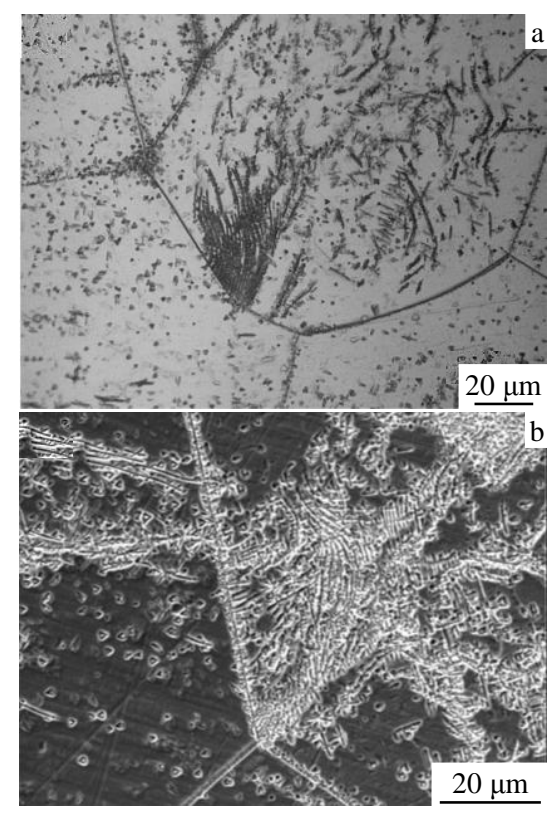

Fig.5 Micrographs demonstrating grain boundary dislocation generation in Ti-7333 alloy deformed at $770{ }^{\circ} \mathrm{C}$ and $1 \mathrm{~s}^{-1}$ to a true strain of 0.02: (a) optical microscope and (b) scanning electron microscope the unlocking of grain boundary dislocation sources through localized dislocation climb, grain boundary migration and/or solute rearrangement. Besides, the high value of the activation energy may be attributed to the solid solution strengthening effect caused by some $\beta$ stabilizers, such as molybdenum and chromium.

\section{Conclusions}

1) The discontinuous yielding of Ti-7333 alloy occurs when its strain rate is above $10^{-2} \mathrm{~s}^{-1}$ at all the experimental temperatures.

2) The magnitude of the discontinuous yield drop for Ti-7333 alloy increases with decreasing of strain rate at a fixed temperature and decreases with decreasing of temperature at fixed strain rate. The magnitude is more sensitive to strain rate than temperature in the present investigation.

3) The discontinuous yielding is associated with grain boundary mobile dislocation generation.

\section{References}

1 Jones N G, R J D D. Metallurgical and Materials Transactions $A[\mathrm{~J}], 2009,40 \mathrm{~A}: 1944$

2 Zhao Yinghui, Ge Peng, Zhao Yongqing et al. Rate Metal Materials and Engineering[J], 2009, 38(1): 46 (in Chinese)

3 Courtney T H. The Mechanical Behavior of Materials[M]. New York: McGraw-Hill, 1992

4 Zeng liying, Yang Guanjun, Ge Peng et al. Rate Metal Materials and Engineering [J], 2010, 39(9): 1505 (in Chinese)

5 Robertson D G, Mcshane H B. Materials Science and Technology[J], 1997, 13(7): 575

6 Weiss I, Semiatin S L. Materials Science and Engineering $[\mathrm{J}]$, 1998, A243: 46

7 Long M, Rack H J. Titanium1995, Science and Technology[C]. London: The Institute of Materials, 1996: 316

8 Han Z, Luo H, Wang H et al. Materials Science and Engineering: $A[\mathrm{~J}], 2011,528(13-14): 4372$

9 Hale C L, Rollings W S, Weaver M L et al. Materials Science and Engineering: $A[\mathrm{~J}], 2001,300(1-2): 153$

10 Kou Hongchao, Lai Minjie, Tang Bin et al. Titanium 2011[C]. Beijing, 2011: 1706

11 NarayanaMurty S V S, Nageswara Rao B. J Mater Process Technol[J], 2000, 104: 103

12 Wang Ruining, Xi Zhengping, Zhao Yongqing et al. Rare Metal Materials and Engineering[J], 2008, 37(8): 1356 (in Chinese)

13 Srinivasan R, Weiss I. The Minerals, Metals and Materials Society[M]. PA: Warrendale, 1993: 283

14 Zhou Wei, Ge Peng, Zhao Yongqing et al. The Chinese Journal of Nonferrous Metals[J], 2010, 20(1): 852 (in Chinese)

15 Raghunathan S L, Dashwood R J, Jackson M et al. Mate Sci Eng $A[\mathrm{~J}], 2008,488(1-2): 8$

16 Bao Ruqiang, Huang Xu, Huang Lijun et al. Journal of Materials Engineering $[\mathrm{J}], 2003,12: 3$ (in Chinese) 
17 Jonas J J, Heritier B, Luton M J. Met Trans A[J], 1979, 10: 611

18 Ankem S, Shyue J G, Vijayshankar M N et al. Materials Science and Engineering: $A[\mathrm{~J}], 1989,111: 51$

19 Zhao Y H, Liao X Z, Jin R et al. Acta Materialia[J], 2004, 52(15): 4589

20 Yang Lina, Zhang Guoying, Luo Zhicheng et al. Journal of
Shenyang Normal University, Natural Science[J], 2009, 01: 46 (in Chinese)

21 Fan Jiangkun, Kou Hongchao, Lai Minjie et al. Advanced Materials Research[J], 2012, 538: 945

22 Dymont E, Libnati C M. J Mater Sci[J], 1968, 3: 349

\title{
新型近 $\boldsymbol{\beta}$ 钛合金 Ti-7333 的高温不连续屈服行为
}

\author{
刹江昆, 寇宏超, 赖敏杰, 唐 斌, 常 辉, 李金山 \\ (西北工业大学 凝固技术国家重点实验室，陕西 西安 710072)
}

\begin{abstract}
摘 要: 对一种新型近 $\beta$ 钛合金 Ti-7333 在温度为 770 845 ${ }^{\circ} \mathrm{C}$, 应变速率为 $10^{-3} \sim 1 \mathrm{~s}^{-1}$ 条件下的高温不连续屈服行为进行了研究。结果表 明: 在试验温度范围内, 当应变速率大于 $10^{-2} \mathrm{~s}^{-1}$ 时, Ti-7333 合金高温变形过程中会出现不连续屈服现象。该合金的不连续屈服幅度随 着应变速率的减小和温度的升高而逐渐增大, 而且屈服的幅度对应变速率较温度更为敏感。通过对不连续屈服现象的显微组织观察可知, 这是由于随着应变的增大, 在晶界处生成的可动位错在塑性变形中向晶粒内部扩展传播所导致, 晶界是这些可动位错的位错源。不连续 屈服现象与位错源局部位错攀移开动传播、晶界迁移以及（或者）合金元素固溶重排过程有关。
\end{abstract}

关键词：Ti-7333；近 $\beta$ 钛合金; 不连续屈服；高温；应变速率；位错

作者简介: 㚞江昆, 男, 1987 年生, 博士, 西北工业大学凝固技术国家重点实验室, 陕西 西安 710072, 电话: 029-88460568, E-mail: fjk2006ok@163.com 